\title{
Histological and immunohistochemical features of the spleen in persistent polyclonal B-cell lymphocytosis closely mimic splenic B-cell lymphoma
}

\author{
Ping Sun ${ }^{1}$ and Ridas Juskevicius ${ }^{2^{*}}$
}

\begin{abstract}
Persistent polyclonal B-cell lymphocytosis (PPBL) is rare and intriguing hematological disorder predominantly reported in young to middle- aged smoking women. It is characterized by persistent moderate polyclonal B-cell lymphocytosis with circulating hallmark binucleated lymphocytes and elevated polyclonal serum IgM. Most patients have benign clinical course on long-term follow-up. Some pathologic features of PPBL may resemble malignant lymphoma, including morphology as well as frequent cytogenetic and molecular abnormalities. Significant symptomatic splenomegaly requiring splenectomy is very unusual for this disorder; therefore there is a lack of descriptions of the morphologic features of the spleen in the literature. We present here one of the first detailed descriptions of the morphologic and immunohistochemical features of the spleen from a young female with PPBL who developed massive splenomegaly during 6 -year follow up. Splenectomy was performed for symptomatic relief and suspicion of malignant process. The morphological and immunohistochemical features of the spleen closely mimicked involvement by B-cell lymphoma, however there was no monotypic surface light chain restriction seen by flow cytometry and no clonal rearrangement of $\mathrm{g} H \mathrm{H}$ gene was detected by molecular analysis. Evaluating a splenectomy sample in cases like this may present a diagnostic challenge to pathologists. Therefore, correlation with B cell clonality studies (by flow cytometry and molecular analysis), clinical findings and peripheral blood morphology searching for characteristic binucleated lymphocytes is essential to avoid misdiagnosing this benign process as B-cell lymphoma. We also present here a literature review on pathogenesis of PPBL.
\end{abstract}

Virtual slides: The virtual slide(s) for this article can be found here: http://www.diagnosticpathology.diagnomx.eu/ vs/5329558967545656

Keywords: Persistent polyclonal B cell lymphocytosis, Splenomegaly, Lymphoma, Binucleated lymphocytes

\section{Background}

Persistent polyclonal B-cell lymphocytosis (PPBL) is a rare clinically benign lymphoproliferative disorder first described by Gordon et al. in 1982 [1]. To date, around 200 cases worldwide have been reported in literature. PPBL is characterized by chronic mild-to-moderate peripheral polyclonal lymphocytosis of B cell origin as evidenced by flow cytometry and variable number of

\footnotetext{
*Correspondence: ridas.juskevicius@vidanthealth.com

2Department of Pathology \& Laboratory Medicine, Brody School of Medicine, East Carolina University, 600 Moye Blvd, Brody Medical Sciences Building

7S-18, Greenville, NC 27858-4353, USA

Full list of author information is available at the end of the article
}

atypical binucleated lymphocytes present on peripheral blood film. The total lymphocyte count is not always elevated in all patients. Due to the hallmark presence of binucleated lymphocytes, this entity is also called B-cell lymphocytosis with binucleated lymphocytes. The majority of patients also demonstrate polyclonal increase in serum IgM. It is most frequently reported in young or middle-aged female smokers [1-6]. Most patients present with mild nonspecific symptoms, such as weakness and fatigue. Mild splenomegaly is a single most frequently reported clinical finding, present in about $10 \%$ of patients according to the largest case series [2]. Massive splenomegaly has been only rarely reported in

\section{() BioMed Central}

(c) 2012 Sun and Juskevicius; licensee BioMed Central Ltd. This is an Open Access article distributed under the terms of the Creative Commons Attribution License (http://creativecommons.org/licenses/by/2.0), which permits unrestricted use, distribution, and reproduction in any medium, provided the original work is properly cited. 
the literature. As most patients have an indolent clinical course and peripheral lymphocytosis is sometimes absent, this condition is likely under-recognized. PPBL resembles malignant lymphoproliferative disorder in many aspects, both morphologically and at the molecular/cytogenetic levels. In addition to the hallmark atypical lymphocytes, the bone marrow of these patients sometimes shows intrasinusoidal distribution of B lymphocytes resembling marrow involvement by splenic marginal zone lymphoma [7]. We here report histological and immunohistochemical features of the spleen in a young female with PPBL who underwent splenectomy due to progressive splenomegaly on her $6^{\text {th }}$ annual follow-up. Very recently, Italian investigators Del Giudice et al. described similar histopathological findings of the spleen in three patients with PPBL and progressive splenomegaly who underwent splenectomy [8]. PPBL can be further confused with a malignant lymphoproliferative disorder as PPBL is frequently associated with chromosomal abnormalities and multiple $B C L 2 / I G$ gene rearrangements as seen in some lymphomas $[9,10]$. To avoid unnecessary aggressive treatment, it is important for pathologists to distinguish this clinically benign disorder from malignant lymphoproliferative disorders.

\section{Case presentation}

The 38-year-old woman with a 20 years history of heavy smoking of $1 \frac{1 / 2}{2}$ packages of cigarettes per day was referred to QEII Health Science Centre, Halifax, Nova Scotia about 6 years ago for investigation of fatigue, frequent colds and persistent lymphocytosis for over 6 months. Her past medical history was unremarkable. The only positive finding on her physical examination was mild splenomegaly with spleen palpable $4 \mathrm{~cm}$ below left costal margin. Her initial complete blood cell count $(\mathrm{CBC})$ showed isolated lymphocytosis of $10.2 \times 10^{9} / \mathrm{L}$ with peripheral blood smears showing few atypical binucleated lymphocytes. Flow cytometry of her peripheral blood revealed an increase in polytypic CD19+/ CD20+/ CD5-/ CD10- B cells. Serum protein electrophoresis showed elevated polyclonal IgM at $9.6 \mathrm{~g} / \mathrm{L}$. The patient was diagnosed with PPBL and was closely monitored by her family physician and local oncologist. Over the following 6 years, she received no medical intervention. Several months prior to her splenectomy, she started complaining of increasing abdominal discomfort. Her spleen slowly increased in size and reached over $8 \mathrm{~cm}$ below left costal margin. She had no hepatomegaly or lymphadenopathy on CT imaging of the neck, chest, abdomen and pelvis. Her CBC remained unchanged with persistent peripheral lymphocytosis varying between 10 to $13 \times 10^{9} / \mathrm{L}$ and showing variable numbers of characteristic binucleated lymphocytes. Repeated flow cytometry of peripheral blood just prior to splenectomy showed persistent increase in polytypic B cells. She subsequently underwent splenectomy for symptomatic relief as well as for suspicion of "malignant transformation". Patient's postoperative course was unremarkable requiring no further therapy. The patient continued heavy smoking throughout her years of follow-up.

\section{Materials and methods}

\section{Histology and immunohistochemistry}

Formalin-fixed, paraffin-embedded tissue sections were stained with hematoxylin and eosin (H\&E) and Periodic Acid-Schiff (PAS). Immunohistochemistry was performed on 4- $\mu \mathrm{m}$-thick sections prepared from formalin-fixed, paraffin-embedded tissue using an automated immunostainer (Bechmark XT, Ventana Medical Systems Inc., Tucson, AZ). The antigenic determinants and probes tested are listed in table 1.

\section{Immunophenotyping by flow cytometry}

Mononuclear cells from fresh peripheral blood were separated by density-gradient centrifugation and were characterized using four-color immunostaining by a FACSCalibur flow cytometer (Becton, Dickinson and Company, San Jose, CA) and Cell Quest software (Becton, Dickinson and Company, San Jose, CA). The following monoclonal antibodies were used: CD45-allophycocyanin (APC), CD5phycoerythrin (PE), CD19-peridinin cholorophyll protein (PerCP), CD20-fluorescin isothiocyanate (FITC), CD22FITC, CD23-FITC, CD38-PE, CD11C-PE, CD10-PE, FMC7-FITC, anti-kappa chain-FITC, anti-lambda chainPE. CD23 and FMC7 were obtained from Beckman Coulter (Miami, FL), and the rest of the monoclonal antibodies were purchased from Becton, Dickinson and Company.

\section{Molecular analysis}

DNA from paraffin-embedded spleen sections was extracted using the commercially available DNA Blood Mini Kit (Qiagen Inc., Mississauga, ON, Canada). B cell

\section{Table 1 List of antibodies/ probes}

\begin{tabular}{lcc}
\hline Antibody/ probe & Source & Dilution \\
\hline CD5 (SP19) & Cell Marque Co., & Predilute \\
CD10 (56C6) & Cell Marque Co., & Predilute \\
CD20 (L26) & Ventana, Arizona, USA & Predilute \\
CD23 (1B12) & Cell Marque Co. & Predilute \\
CD43 (L60) & Ventana, Arizona, USA & Predilute \\
Cyclin D1(SP4) & Medicorp, Montreal, Canada & $1 ; 50$ \\
BCL-2 (124) & DAKO, Mississauga, Canada & $1: 40$ \\
Kappa & DAKO, Mississauga, Canada & $1: 20,000$ \\
Lambda & DAKO, Mississauga, Canada & $1: 20,000$ \\
EBER (RNA probe) & Ventana, Arizona, USA & Predilute \\
\hline
\end{tabular}


clonality was assessed using nested PCR with consensus primers for the variable and joining regions as described by Reed et al. [11]. This approach is reported to detect $83 \%$ of immunoglobulin heavy chain gene rearrangements. T-cell clonality was similarly assessed using PCRbased method for T-cell receptor $\gamma$ gene rearrangement described by Diss et al. [12]. Two reactions with primers $\mathrm{VgI}$ and VgIII/IV and Jg1/2 are reported to detect $80 \%$ of T-cell gamma gene rearrangements. A nested PCR was also used to detect $B C L 2 / I G$ gene rearrangement targeting the usual breakpoint regions of the $t(14 ; 18)$.

\section{Results}

Grossly, the spleen was enlarged, weighing 519 grams and measuring $16 \times 11 \times 6.5 \mathrm{~cm}$. The splenic capsule was well preserved. Histologically, the spleen architecture was altered with expansion of the white pulp nodules by small mature lymphocytes with no prominent germinal center formations identified (Figure 1 - A, B). The white pulp nodules in some areas demonstrated fusion but no apparent or distinct marginal zones were present. There was also a massive infiltration of red pulp by similar-appearing small lymphocytes that were located both within the sinusoids and splenic cords (Figure 1 - C, D). Occasional binucleated lymphocytes were noted in the splenic sinusoids (black arrows in Figure 1 - C, D and inset). No large transformed lymphoid cells were identified and plasma cells were not prominent.

Immunohistochemical analysis demonstrated massive amount of CD20+/ BCL-2+/ CD43+ B cells located both within the white pulp nodules as well as within the red pulp (CD20 and BCL-2 stains shown in Figure 2 - B and $\mathrm{C}$ respectively). These $\mathrm{B}$ cells were negative for $\mathrm{CD} 10$, CD23, CD5, and cyclin D1. Only few CD3+ T cells were present in the red and white pulp (Figure 2 - A). Scattered plasma cells were polytypic using Kappa and Lambda light chain stains and no monotypic restriction was identified within the B lymphocytes. No EBV was detected using EBER in situ hybridization.

Molecular analysis on paraffin- embedded spleen sample did not demonstrate clonal rearrangements of the immunoglobulin heavy chain genes (Figure $2-\mathrm{D}$ ) or

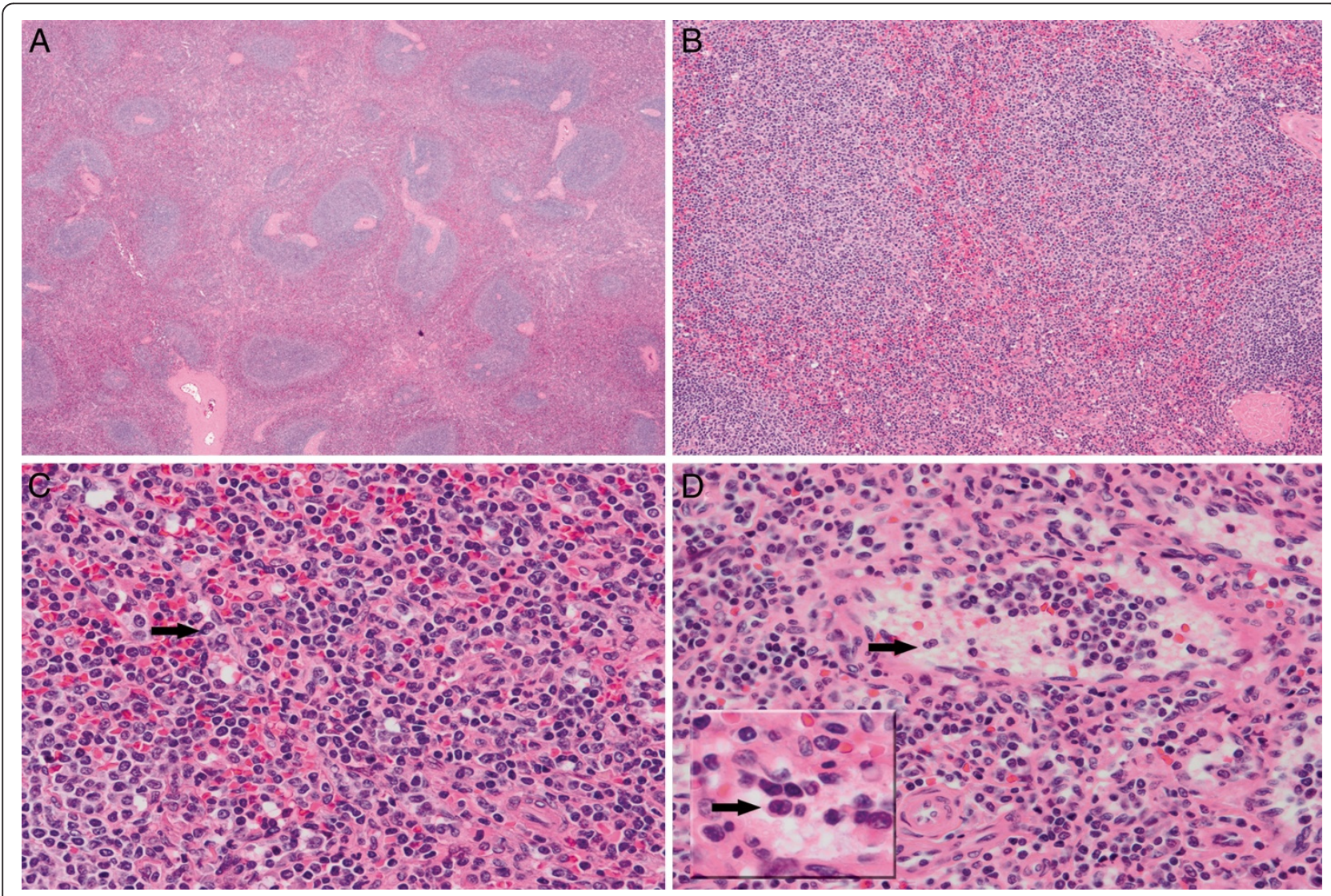

Figure 1 Histological features of the spleen. Images of the H\&E stained spleen sections at 20x (A), 100x (B) and 400x (C, D) magnification showing expansion of the white pulp nodules and significant infiltration of the red pulp by small mature lymphocytes with minimal cytologic atypia. Occasional binucleated lymphocytes are noted in the splenic sinusoids indicated by black arrows (C, D and D inset). 


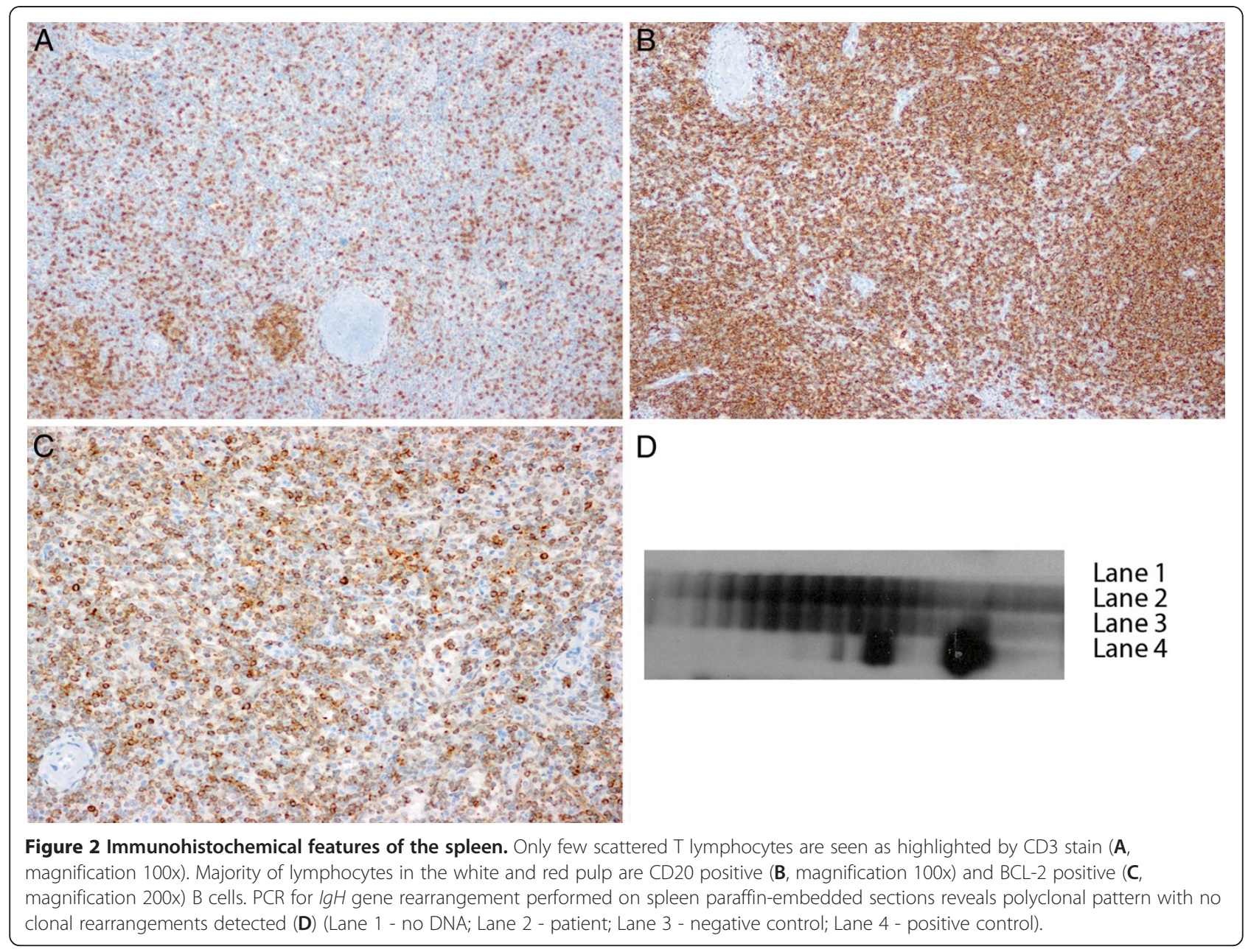

T-cell receptor gamma gene. No BCL2 gene rearrangements were detected.

\section{Discussion}

PPBL is an uncommon disorder characterized by an indolent and benign clinical course with persistent polyclonal B-cell lymphocytosis and circulating binucleated lymphocytes as well as increased polyclonal serum IgM. There are only rare reports of PPBL in association with malignant lymphoma or with secondary solid cancers $[2,3,13]$. Since the first description in 1982, about 200 cases have been reported in the literature.

The majority of the reports focus on the study of PPBL pathogenesis, which remains unclear. Although most frequently detected in smokers, PPBL is also occasionally observed in non-smokers. The association with viral infections, such as Epstein-Barr virus, is still a matter of debate [3,14-16]. The polyclonal B cells which are expanded in this disorder appear to be CD27+/IgM+/IgD + memory B cells, which may result from chronic antigenic stimulation $[4,17]$. PPBL is frequently linked with HLA-DR7 haplotype
[18-20]. Cases of familial PPBL and the incidence of PPBL in monozygotic twins are suggestive of a strong genetic predisposition [21,22]. It is reasonable to speculate that the interaction of genetic predisposition with chronic antigenic stimulation may lead to the development of PPBL. Very recently, whole genome microarray expression analysis was done in 14 PPBL patients, which demonstrated over-expression of AP-1 transcription complex and downregulation of Fas-apoptotic and TGF $\beta$ pathway [5]. The polyclonality of the lymphocyte population evidenced by flow cytometry in this disorder is challenged by rare reports of clonal IGHD-IGHJ immunoglobulin rearrangement in patients otherwise meeting diagnostic criteria of PPBL $[6,23]$. These findings suggest that polyclonal expansion may be followed by the emergence of predominant clone in rare cases.

PPBL mimics malignant lymphoma morphologically. Variable amount of hallmark atypical lymphocytes are invariably present in peripheral circulation. Bone marrow changes in the PPBL patients described earlier demonstrate an interstitial, particularly intrasinusoidal B 
cells mimicking those seen in B-cell lymphoproliferative disorders especially in splenic marginal zone lymphoma [7]. However, the intravascular or intrasinusoidal pattern of the $\mathrm{B}$ cell distribution in the bone marrow is most likely a reflection of the peripheral lymphocytosis and the recirculating nature of the lymphocytes in this benign disorder. Mild splenomegaly is the most frequently reported physical finding, which is detected in about $10 \%$ of patients according to the largest case series [2]. Massive splenomegaly is rare among these patients. Our PPBL patient reported here manifested slowly progressive splenomegaly during six years of follow-up. Her spleen contained massive amount of CD20+/BCL-2+ B cells within the red and white pulp mimicking B-cell lymphoma. In their series of 5 patients Del Giudice et al. from Italy recently reported very similar findings to ours in three of their five PPBL patients who developed massive splenomegaly and underwent splenectomy [8]. The B cells present both in bone marrow and spleen show same immunophenotype including expression of BCL-2 $[7,8]$. In addition, the B cells in our patient were also positive for CD43. CD43 expression was not studied by Del Giudice $e t$ al. and CD43 was negative in the bone marrow reported by Feugier et al. [7]. Although expression of CD43 by B cells is often used as a marker in favor of a B-cell lymphoproliferative disorder, it has been recognized that CD43 can be expressed by $B$ cells in benign conditions [24,25]. Except splenomegaly, no other abnormal physical or radiographic findings suggestive of malignant lymphoma transformation were detected in our patient and the five patients reported by Del Giudice et al. Therefore, the histological and immunophenotypic findings observed in the spleens of these PPBL patients are most likely a reflection of their underlying benign PPBL process.

PPBL also mimics lymphoma at cytogenetic and molecular level. The chromosomal abnormalities are frequently reported in PPBL patients. Isochromosome $+\mathrm{i}(3 \mathrm{q})$ is the most common chromosomal abnormality and is present in $71 \%$ of cases when using the most sensitive fluorescence in situ hybridization (FISH) method [2]. Other less common chromosomal abnormalities include trisomy 3, premature chromosome condensation (PCC) and chromosome instability $[2,9,10]$. Among the above mentioned chromosomal abnormalities, trisomy 3 has been reported to be associated with marginal zone lymphomas (MZL) and mantle cell lymphoma (MCL) [26,27]. Cytogenetic studies on our patient using FISH were performed on the peripheral blood sample collected during one of the follow up visits and demonstrated no abnormalities of chromosome 3. Although not detected in our patient, $B C L 2 / I g H$ gene rearrangements as seen in follicular lymphoma have been reported in some PPBL patients by using PCR technique $[7,10,28]$.

\section{Conclusions}

Our report adds to the extremely limited literature about the histopathologic features of PPBL; to our knowledge this is one of the first detailed descriptions of spleen pathology in a patient with PPBL. Both histological and immunohistochemical findings were misleading and mimicked B cell lymphoma. To avoid misdiagnosing this process as B-cell lymphoma, which may lead to unnecessary treatment, it is important to recognize the misleading histology and somewhat unusual phenotype, assess clonality and to be aware of the cytogenetic and molecular abnormalities that may be associated with this intriguing but benign entity.

\section{Ethical approval}

This case report was based on the existing data, and the patients' identification was kept confidential in this study. This case report does not meet definition of human or animal subject research by University and Medical Center Institutional Review Board of East Carolina University and University of Manitoba, and no ethical approval was necessary for this study.

\section{Competing interests}

Both authors declare that they have no competing interests.

\section{Authors' contributions}

PS performed literature review, patient records review and drafted the manuscript. RJ conceived of the study, participated in its design and coordination, helped to draft and edited the manuscript and created the figures. PS and RJ were directly involved in the diagnosis and care of the patient. All authors read and approved the final manuscript.

\section{Author details}

1Division of Hematopathology, Diagnostic Services of Manitoba, University of Manitoba, MS559S-820 Sherbrook Street, Winnipeg R3A 1R9MB, Canada. ${ }^{2}$ Department of Pathology \& Laboratory Medicine, Brody School of Medicine, East Carolina University, 600 Moye Blvd, Brody Medical Sciences Building 7S-18, Greenville, NC 27858-4353, USA.

Received: 26 June 2012 Accepted: 10 August 2012

Published: 19 August 2012

\section{References}

1. Gordon DS, Jones BM, Browning SW, Spira TJ, Lawrence DN: Persistent polyclonal lymphocytosis of B lymphocytes. N Engl J Med 1982, 307(4):232-236.

2. Cornet E, Lesesve JF, Mossafa H, Sebahoun G, Levy V, Davi F, Troussard X: Long-term follow-up of 111 patients with persistent polyclonal B-cell lymphocytosis with binucleated lymphocytes. Leukemia 2009, 23(2):419-422.

3. Schmidt-Hieber M, Burmeister T, Weimann A, Nagorsen D, Hofmann WK, Thiel E, Schwartz S: Combined automated cell and flow cytometric analysis enables recognition of persistent polyclonal B-cell lymphocytosis (PPBL), a study of 25 patients. Ann Hematol 2008, 87(10):829-836.

4. Himmelmann A, Gautschi O, Nawrath M, Bolliger U, Fehr J, Stahel RA: Persistent polyclonal B-cell lymphocytosis is an expansion of functional IgD(+)CD27(+) memory B cells. Br J Haematol 2001, 114(2):400-405.

5. Lawrie $\mathrm{CH}$, Shilling $\mathrm{R}$, Troussard $X$, Cattan $H$, Mossafa $H$, Pezzella $F$, Boultwood J, Wainscoat JS, Hatton CS: Expression profiling of persistent polyclonal B-cell lymphocytosis suggests constitutive expression of the AP-1 transcription complex and downregulation of Fas-apoptotic and TGFbeta signalling pathways. Leukemia 2009, 23(3):581-583. 
6. Wolowiec D, Nowak J, Majewski M, Haus O, Duszenko E, Stella-Holowiecka B, Mika-Witkowska R, Makuch-Lasica H, Nowak G, Krawcewicz A, et al: High incidence of ancestral HLA haplotype 8.1 and monoclonal incomplete $\mathrm{DH}-\mathrm{JH}$ immunoglobulin heavy chain gene rearrangement in persistent polyclonal B-cell lymphocytosis. Ann Hematol 2008, 87(7):597-598.

7. Feugier P, De March AK, Lesesve JF, Monhoven N, Dorvaux V, Braun F, Gregoire MJ, Jonveaux P, Lederlin P, Bene MC, et al: Intravascular bone marrow accumulation in persistent polyclonal lymphocytosis: a misleading feature for B-cell neoplasm. Mod Pathol 2004, 17(9):1087-1096.

8. Del Giudice I, Pileri SA, Rossi M, Sabattini E, Campidelli C, Starza ID, De Propris MS, Mancini F, Perrone MP, Gesuiti P, et al: Histopathological and molecular features of persistent polyclonal B-cell lymphocytosis (PPBL) with progressive splenomegaly. Br J Haematol 2009, 144(5):726-731.

9. Mossafa H, Tapia S, Flandrin G, Troussard X: Chromosomal instability and ATR amplification gene in patients with persistent and polyclonal B-cell lymphocytosis (PPBL). Leuk Lymphoma 2004, 45(7):1401-1406.

10. Delage $R$, Roy J, Jacques $L$, Bernier $V$, Delage JM, Darveau A: Multiple bcl-2/ Ig gene rearrangements in persistent polyclonal B-cell lymphocytosis. $\mathrm{Br}$ J Haematol 1997, 97(3):589-595.

11. Reed TJ, Reid A, Wallberg K, O'Leary TJ, Frizzera G: Determination of B-cell clonality in paraffin-embedded lymph nodes using the polymerase chain reaction. Diagn Mol Pathol 1993, 2(1):42-49.

12. Diss TC, Watts M, Pan LX, Burke M, Linch D, Isaacson PG: The polymerase chain reaction in the demonstration of monoclonality in $T$ cell lymphomas. J Clin Pathol 1995, 48(11):1045-1050.

13. Lawlor E, Murray M, O'Briain DS, Blaney C, Foroni L, Sarsfield P, Condell D, Sullivan F, McCann SR: Persistent polyclonal B lymphocytosis with Epstein-Barr virus antibodies and subsequent malignant pulmonary blastoma. J Clin Pathol 1991, 44(4):341-342.

14. Chow KC, Nacilla JQ, Witzig TE, Li CY: Is persistent polyclonal B lymphocytosis caused by Epstein-Barr virus? A study with polymerase chain reaction and in situ hybridization. Am J Hematol 1992, 41(4):270-275

15. Larcher C, Fend F, Mitterer M, Prang N, Schwarzmann F, Huemer HP: Role of Epstein-Barr virus and soluble CD21 in persistent polyclonal B-cell lymphocytosis. Br J Haematol 1995, 90(3):532-540.

16. Larcher C, McQuain C, Berger C, Mitterer M, Quesenberry PJ, Huemer HP, Knecht H: Epstein-Barr virus-associated persistent polyclonal B-cell lymphocytosis with a distinct 69-base pair deletion in the LMP1 oncogene. Ann Hematol 1997, 74(1):23-28.

17. Loembe MM, Neron S, Delage R, Darveau A: Analysis of expressed V(H) genes in persistent polyclonal $B$ cell lymphocytosis reveals absence of selection in CD27 + IgM + lgD + memory B cells. Eur J Immunol 2002, 32(12):3678-3688.

18. Callet-Bauchu E, Gazzo S, Poncet C, Pages J, Morel D, Alliot C, Coiffier B, Coeur $P$, Salles G, Felman P: Distinct chromosome 3 abnormalities in persistent polyclonal B-cell lymphocytosis. Genes Chromosomes Cancer 1999, 26(3):221-228.

19. Callet-Bauchu E, Renard N, Gazzo S, Poncet C, Morel D, Pages J, Salles G, Coeur P, Felman P: Distribution of the cytogenetic abnormality $+i(3)(q 10)$ in persistent polyclonal B-cell lymphocytosis: a FICTION study in three cases. Br J Haematol 1997, 99(3):531-536.

20. Troussard $X$, Valensi F, Debert C, Maynadie M, Schillinger F, Bonnet $P$, Macintyre EA, Flandrin G: Persistent polyclonal lymphocytosis with binucleated B lymphocytes: a genetic predisposition. Br J Haematol 1994, 88(2):275-280.

21. Himmelmann A, Ruegg R, Fehr J: Familial persistent polyclonal B-cell lymphocytosis. Leuk Lymphoma 2001, 41(1-2):157-160.

22. Carr R, Fishlock K, Matutes E: Persistent polyclonal B-cell lymphocytosis in identical twins. Br J Haematol 1997, 96(2):272-274.

23. Chan MA, Benedict SH, Carstairs KC, Francombe WH, Gelfand EW: Expansion of B lymphocytes with an unusual immunoglobulin rearrangement associated with atypical lymphocytosis and cigarette smoking. Am J Respir Cell Mol Biol 1990, 2(6):549-552.

24. Lee PS, Beneck D, Weisberger J, Gorczyca W: Coexpression of CD43 by benign $B$ cells in the terminal ileum. Appl Immunohistochem Mol Morphol 2005, 13(2):138-141.

25. Björck P, Axelsson B, Paulie S: Expression of CD40 and CD43 during activation of human B lymphocytes. Scand J Immunol 1991, 33(2):211-218.

26. Dierlamm J, Pittaluga S, Wlodarska I, Stul M, Thomas J, Boogaerts M, Michaux L, Driessen A, Mecucci C, Cassiman JJ: Marginal zone B-cell lymphomas of different sites share similar cytogenetic and morphologic features. Blood 1996, 87(1):299-307.

27. Bea S, Ribas M, Hernandez JM, Bosch F, Pinyol M, Hernandez L, Garcia JL, Flores T, Gonzalez M, Lopez-Guillermo A, et al: Increased number of chromosomal imbalances and high-level DNA amplifications in mantle cell lymphoma are associated with blastoid variants. Blood 1999, 93(12):4365-4374.

28. Delage $R$, Roy J, Jacques $L$, Darveau A: All patients with persistent polyclonal $B$ cell lymphocytosis present $\mathrm{Bcl}-2 / \mathrm{lg}$ gene rearrangements. Leuk Lymphoma 1998, 31(5-6):567-574.

doi:10.1186/1746-1596-7-107

Cite this article as: Sun and Juskevicius: Histological and immunohistochemical features of the spleen in persistent polyclonal Bcell lymphocytosis closely mimic splenic B-cell lymphoma. Diagnostic Pathology 2012 7:107.

\section{Submit your next manuscript to BioMed Central and take full advantage of:}

- Convenient online submission

- Thorough peer review

- No space constraints or color figure charges

- Immediate publication on acceptance

- Inclusion in PubMed, CAS, Scopus and Google Scholar

- Research which is freely available for redistribution 